\title{
Creation and recreation: motivating collaboration to generate knowledge capital in online communities
}

\author{
Hazel Hall ${ }^{\mathrm{a}, *}$, Dianne Graham ${ }^{\mathrm{b}}$ \\ ${ }^{\text {a }}$ School of Computing, Napier University, 10 Colinton Road, Edinburgh EH10 5DT, UK \\ ${ }^{\mathrm{b}}$ Highland Council Harbours, Lochinver Harbour, Lochinver, Sutherland IV27 4LE, UK
}

\begin{abstract}
The results of a research project that examined the factors that motivated individuals competing to win an award of $£ 10,000$ to interact collectively in a Yahoo e-group are presented. The project was the apparent willingness of competitors to help their rivals when only one prize was available. The findings revealed that the initial impetus for members to join the group was to discover information for personal benefit. Over time, however, individual desire to reciprocate the help received from the group developed out of the online interactions. Other results from the study

- challenge the findings of previous research on the value of strong social capital in online communities;

- confirm that in order to motivate active participation in online environments incentives offered should match the values of the group in question;

- advocate that a balance needs to be achieved in determining the degree of focus in a discussion group's activities: a narrow focus leads to action amongst members and diminishes the requirement for social support and community control;

- reveal that decisions on a community's size may determine its power to support genuine collaboration and new knowledge creation: all-inclusive membership provides opportunities for individual learning, but true knowledge capital is generated in smaller, less public groups.
\end{abstract}

These findings highlight issues that businesses may wish to consider when there are plans to create virtual communities of practice to meet corporate goals. This is particularly important with reference to furnishing environments where employees are willing to work collaboratively in the creation of new knowledge.

This article is based in part on a paper presented at The Sixth International Virtual Communities Conference, Church House Conference Centre, Westminster, London, 16-17 June 2003.

(C) 2004 Elsevier Ltd. All rights reserved.

Keywords: Online communities; Knowledge sharing; Incentives; Collaboration

\footnotetext{
*Corresponding author. Tel.: + 44-131-455-2760; fax: +44-131-455-2727.

E-mail addresses: h.hall@napier.ac.uk (H. Hall),dianne.graham@highland.gov.uk (D. Graham).

URL: http://www.bim.napier.ac.uk/ hazel/esis/hazel.html.
} 


\section{Introduction}

This article reports on a research project that examined the motivations of over 2500 code breaking enthusiasts distributed world-wide to join together as an e-group for the purposes of knowledge sharing. The internet-based social aggregation created through the public e-group discussions matches Rheingold's definition of a virtual community (Rheingold, 1994, p. 1). The egroup also exhibited key characteristics of the organisational form known as the community of practice (CoP) (Davenport \& Hall, 2002). It encouraged

- situated action: the work of the e-group centred around ad hoc problem solving,

- situated learning: novices who had less to contribute were able to learn through interactions with experts who contributed much,

- distributed cognition: there was potential for knowledge to be generated collectively by individuals who could not achieve the same if working on their own.

Virtual space provided in a Yahoo e-group served as the supporting IT infrastructure for the community's interactions. From the outset the e-group's mode of "management" tallied with that of a CoP (Wenger \& Snyder, 2000). It was set up

- for informal interactions: the members of the e-group had no formal connection to one another,

- for work to be driven by the desire to share expertise: the members wanted to share knowledge on code-breaking,

- without an agenda imposed from outside: the operation of the e-group was determined by the membership,

- with the expectation that it would find its own shape: the e-group's "shape" developed over time,

- so that it could be sustained by the passion and interests of the participants: the health of the egroup was dependent on membership's enthusiasm.

To set the context for the research project's main findings this article begins with a summary of recent work on factors that encourage knowledge sharing in electronic environments. This is followed by a description of the CipherChallenge, the original impetus for the group's formation. The extent to which the results of the work might inform the operation of virtual communities in more "serious" settings is then explored.

\section{Communities, collaborative work and motivating knowledge sharing}

Much of the literature on CoPs is concerned with enhancing collaborative work at the level of a single organisation (for example, Huberman \& Hogg, 1994) or networks of organisations (for example, Huang, Newell, \& Galliers, 2002). It is generally accepted that such "collaborative work" in these communities depends on the encouragement of knowledge sharing between parties. Therefore, several studies from the early 1990s onwards (for example, Constant, Kiesler, \& Sproull, 1994) have sought to understand the factors that encourage and inhibit knowledge sharing in environments where extensive use is made of technology. More recently this work has considered, for example, knowledge sharing with reference to collaborative software development (Lerner \& Tirole, 2002) and economic self-interest in discussion groups (Gray \& Meister, 2001, 
May), as well as attempted to model transactions that occur when parties collaborate in communities (Faraj \& Wasko, c2001).

Reviews of published work on incentives for knowledge sharing discuss the factors that motivate knowledge exchange (Hall, 2001a,b, in press). These range from deliberate managerial interventions in the corporate environment, such as the use of reward systems, to the provision of suitable supporting infrastructure. Table 1 summarises rewards as incentives for knowledge sharing. In Table 2, three broad infrastructure categories that support knowledge sharing are introduced: social, technological and boundary.

Researchers have concluded that knowledge sharing is more likely to occur when individuals hold strong beliefs about organisational ownership of their information and expertise (Jarvenpaa \& Staples, 2001, p. 165), and when a positive attitude towards knowledge sharing is promoted within the organisation (Bock \& Kim, 2002). These conclusions apply to the business environment where individuals are bound into a particular set of operations with a common corporate goal. The degree to which they are applicable in a "social" or recreational setting in which participants have no work-based commitments to one another was of interest to the study described in this article.

\section{Background to the CipherChallenge}

Simon Singh, the British journalist and television producer, is well known for his 1997 bestseller, Fermat's last theorem. On 2 September 1999 Singh published The code book (Singh, 1999). Most of the book is dedicated to the history of cryptography and illustrated by several cases. It includes, for example, the story of how Mary, Queen of Scots, became trapped by her own code and how this led to her execution, and the role of code making and code breaking in the two World Wars. At the end of the book Singh announced the CipherChallenge. He would award $£ 10,000$ to the first reader who was able to break the 10 codes given on pp. 353-366. Fig. 1 provides an example of one of the codes to be cracked.

Among the reasons for publishing his book, Singh was interested to see whether new codebreaking techniques would be developed by those who took up his challenge (Singh, 2000). Two months after publication a code-breaker set up a Yahoo e-group "to provide a focus for discussions about the CipherChallenge" (Welcome, 1999). By the time that the research described in this article was carried out, the discussion group's membership of over 2500 enthusiasts had

Table 1

Rewards as incentives for knowledge sharing (Source: Hall, 2001a, pp. 142-144)

\begin{tabular}{lll}
\hline Reward category & Reward & Examples \\
\hline Hard/explicit rewards & $\begin{array}{l}\text { Economic reward } \\
\text { Access to information and knowledge, } \\
\text { i.e. learning opportunities } \\
\text { Career advancement/security }\end{array}$ & Enhanced pay, stock options, bonuses \\
& Expertise from members of a mailing list \\
& Personal satisfaction & Promotion, guarantees of future contracts \\
Soft rewards & Status gains & Seeing the positive results of helping others
\end{tabular}


Table 2

Provision of suitable infrastructures to incentivise knowledge sharing (Source: Hall, 2003, p. 300)

\begin{tabular}{|c|c|c|}
\hline $\begin{array}{l}\text { Infrastructure } \\
\text { category }\end{array}$ & Condition & Examples \\
\hline \multirow[t]{4}{*}{ Social } & Create a sense of community & $\begin{array}{l}\text { Promotion of openness, co-operation, } \\
\text { loyalty, trust; provision for social } \\
\text { interaction. } \\
\text { Co-location of individuals. }\end{array}$ \\
\hline & $\begin{array}{l}\text { Make knowledge sharing an explicit } \\
\text { responsibility }\end{array}$ & Buy-in from all. \\
\hline & Relegate status & $\begin{array}{l}\text { Promotion of the idea that everyone is a } \\
\text { knowledge contributor, regardless of rank. }\end{array}$ \\
\hline & Encourage experimentation & Provision of autonomy, permission to fail. \\
\hline \multirow[t]{3}{*}{ Technological } & Provide user-friendly systems & Ease of use; usefulness of use obvious. \\
\hline & Ensure that systems integrate with communities & $\begin{array}{l}\text { Systems used in conjunction with "human" } \\
\text { interaction. }\end{array}$ \\
\hline & Generate critical mass & Value of system seen to be monitored. \\
\hline Boundary & $\begin{array}{l}\text { Provide for artefacts, people or spaces that can } \\
\text { act as common points of reference for different } \\
\text { group constituencies }\end{array}$ & $\begin{array}{l}\text { Provision of shared repositories. } \\
\text { Provision of taxonomies and } \\
\text { classification schemes. } \\
\text { Shared social space. } \\
\text { Opportunities for individuals to become } \\
\text { networked with one another. }\end{array}$ \\
\hline
\end{tabular}

${ }^{a}$ The concept of the boundary object was introduced by Star and Griesemer (1989). Practical applications of boundary objects as tools for knowledge sharing are found in the literature of several domains, for example: accounting (Briers \& Chua, 2001); artificial intelligence (Strubing, 1998); design engineering (Henderson, 1998); history of science (Galison, 1997); information science (e.g., Albrechtsen \& Jacob, 1998; Robinson, 2000). information systems (Harvey \& Chrisman, 1998); organizational science (Boland \& Tenkasi, 1995).

included school children, amateur code breakers and professionals. They had used the e-group to exchange messages providing hints, ideas, support and encouragement about the CipherChallenge. The e-group might be considered an organic community in that it grew out of the genuine passion of its members and was not tightly controlled (This contrasts strongly with many "managed" communities instigated in the work place.) Contributions to the e-group peaked with 712 contributions in October 2000, the month that the challenge was won by five Swedes ${ }^{1}$ (who, along the way, had rewritten the number field sieve algorithm, thus meeting Singh's hope that participants in the challenge might develop new techniques for code breaking (Singh, 2000)).

\section{Research conducted with members of the CipherChallenge e-group}

Of particular interest to the study was the tension between the goal of each participant to win the $£ 10,000$ prize and the apparent willingness of individuals to help their rivals. What were the

\footnotetext{
${ }^{1}$ For details on how they cracked the codes see http://answers.codebook.org.
} 


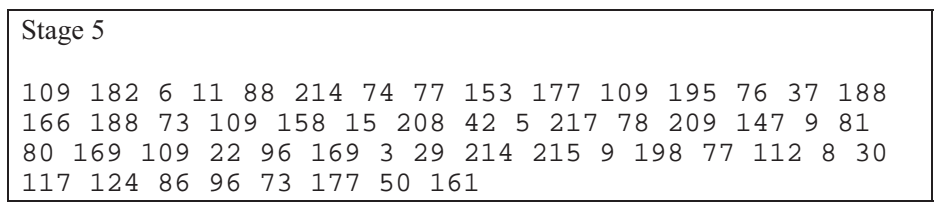

Fig. 1. Stage 5 of the CipherChallenge (Source: Singh, 1999, p. 355).

factors that motivated weakly tied individuals, located in a virtual community, working towards a goal that only one (or one set) could achieve, to share valuable knowledge? How important were social interactions to the workings of the group? Several approaches were used to gather data for the study: (1) a form of content analysis, (2) survey by questionnaire and (3) in-depth interviews.

Firstly, the nature of postings to the e-group was studied and analysed. Although it would be an exaggeration to say that this process was one of "content analysis" in the strictest sense of the term (Denscombe, 1998, pp. 167-168), this exercise provided an understanding of the balance between requests for, and supplies of, information and support amongst the e-group's membership. It also set a context against which the data collected by survey and interview could be analysed.

Systematic random sampling was used to identify 100 participants for the survey. A response rate of $30 \%$ was achieved. It was believed that, although small, this sample gave an honest representation of the population being studied. The questionnaire was designed to elicit data on motivations to join the e-group, perceived benefits of membership (in terms of both learning and support) and levels of participation. Demographic data provided an indication of the participants' level of code-breaking knowledge, their sex and age. The majority of respondents were males under the age of 40 who classed themselves as beginner code breakers.

Many of those who filled in the questionnaire said that they would be willing to engage in follow-up interviews. Unfortunately, it was not practical to follow up all these offers due to difficulties of contacting volunteers located outside the UK (for example in identifying a convenient time for a telephone interview, and the cost of telephone calls). However, eight indepth interviews were conducted with e-group participants. In addition, Singh agreed to be interviewed for the study.

\section{Motivation to participate: accessing knowledge and social relationships in the CipherChallenge e-group}

\subsection{Incentives for participation}

From observations of the postings to the e-group, and from the discussion with Singh (interview, 12 April 2001), it was suspected that potential access to knowledge to help break the codes was of greater interest to e-group participants than the opportunity to help others or meet new people. This was confirmed in the findings from the questionnaire results: two of the top three initial reasons for joining the list were to gain knowledge about code breaking in general, and to help solve a particular problem with a stage of the challenge. All respondents agreed that the 
e-group membership had enhanced their knowledge of code breaking both in terms of learning about (1) general techniques and (2) how to tackle individual components of the task set. Seventyseven percent believed that e-group membership provided an advantage over other code breakers who had not joined up. The third most popular reason for joining the group, rated equally with looking for help with a particular problem, was for benchmarking individual progress, i.e. to find out the stages reached by the other code breakers. This was very important to the winning team:

We quickly joined in order to keep track of the progress of the others, and to take part in the discussions... We actually had decided not to openly discuss our progress. The main reason for not disclosing anything about our progress to the list was that we at a certain point had decided that we were in the contest in order to win it. Once we had decided that, we actually felt that it was a better strategy not to advise the world of how far we had proceeded: Knowledge about how many people have cracked a certain stage can give an indication of how hard it is.

(Almgren, Andersson, Granlund, Ivansson, \& Ulfberg, 2000, p. 5)

Whilst seeking help was an initial motivation for e-group membership the provision of help was not. However, the obligation to share knowledge in return for knowledge gain was an issue for egroup members. It became a reason to revisit the forum. This is discussed in further detail below.

Previous research ${ }^{2}$ has concluded that it is not just information or knowledge that individuals seek in virtual communities. Many are looking for instant access to on-going relationships with a large number of other people. Individuals seek new friends. Groups of enthusiasts want to establish a sense of belonging through shared identities, relationships and commitments. In this case it would appear that participants were not interested in either of these forms of companionship. This contrasts strongly with studies of other online communities, particularly those of young people who develop their online interactions into real romantic encounters (for example, Rettstatt, 2003; Shabka, 2003). The least frequently cited reason for joining the e-group was the expectation of meeting new people. However, this does not mean that the social aspect of participation was unimportant to the e-group's membership. Members of the CipherChallenge e-group readily admitted that they benefited from the encouragement and support of one another in that it spurred them on to continue with the challenge: over two-thirds of the questionnaire respondents said that they were motivated through the group's interactions. This encouragement came in different forms. For example, it was offered in direct appeals to struggling members to keep going. Another form of social support was embedded in the combined knowledge capital of the group manifest in archived messages. ${ }^{3}$ One questionnaire respondent explained:

I gained heart from reading all the old posts from people who would solved the various codes already. It was obviously a do-able task.

\subsection{The incentives balance}

It is evident that although motivation to participate was ostensibly to share knowledge by working collaboratively, personal gain - to access help with particular problems, and support and encouragement from others-was a more important factor for engagement. It is worth

\footnotetext{
${ }^{2}$ See for example, the work of Howard Rheingold at http://www.rheingold.com/index.html.

${ }^{3}$ Indeed, the archive might be considered a boundary object as a repository of the e-group's collective knowledge.
} 
considering why the enhancement of individual learning was the primary motivation for joining the group, and how contributing back to the forum became an issue amongst participants. In addition, explanations for the low importance of relationship-building merits consideration. This third aspect is particularly interesting given that other work on electronic environments emphasises the role of strong social bonds in successful virtual communities.

Perhaps the simplest explanation as to why potential knowledge gain was the main reason for individuals to subscribe to the e-group was that they were competing for an award of $£ 10,000$. They believed that they could use this electronic resource to help win the prize. The frequency with which questionnaire respondents highlighted the interest in benchmarking their own progress supports this theory. Considering this in terms of knowledge sharing, it would appear that egroup members were initially attracted to e-group membership by the element of "take" permitted in a sharing relationship. It is clear, however, that return visits to the forum were prompted by the desire to give back to the community. Some postings to the e-group reveal the development of a collective "morality" based on reciprocity. Many participants shared their knowledge on the assumption that they would receive some kind of reward in return, if not from the person helped, but from another community member. As one interviewee stated:

I think people shared out of a sort of communal interest. They did not want to be selfish... There was a naive community spirit, working to beat a common foe.

E-group members recognised the importance of reciprocal give and take in the list discussions. This is shown in two types of postings: (1) requests for information in the present accompanied with an offer to contribute back in the future, and (2) expressions of frustration at lurkers and free-riders. These, combined with occasional articulations of praise for significant contributors, may be seen as efforts to promote knowledge sharing as good citizenship behaviour, thus providing for the e-group a form of social infrastructure as summarised in Table 2. It is worth noting here, however, that the context for knowledge sharing in this case actually permitted lurking. Firstly, a degree of free-riding was inevitable: novice code breakers could not be expected to provide the same amount of advice as those who were expert. Secondly, since the group's membership was unrestricted, anyone was entitled to indulge in "legitimate peripheral participation" (Lave \& Wenger, 1991). The five Swedes took advantage of this: using the search facility with each of their surnames on the e-group web page it can be seen that between them they only made 13 contributions to the discussion list up until the announcement of their win.

It should also be remembered that copious contributions are not always welcome in electronic environments. There was the danger in this group that enthusiastic information providers might give away too much in their attempts to "help". They had to take care not to issue spoilers that would ruin the enjoyment of those hoping to break the codes on their own. Equally, it is a mistake to assume that high contributors to a forum such as the CipherChallenge e-group are altruistic, expecting nothing in return for what they give. The soft rewards of personal satisfaction and enhanced reputation (as outlined in Table 2 above) are important motivational factors for those who wish to be appreciated or admired (In the CipherChallenge these represented more immediate gains than the $£ 10,000$ prize and were attractive to a set of individuals engaged in an activity where superior intellectual prowess was highly valued.) Singh (interview, 12 April 2001) also acknowledged that it was worth examining the nature of material that the e-group's members 
were willing to share. He observed that anything that was relatively easy to find was readily passed on:

They exchanged a lot of comment such as "Did you know that...?" However, I do not think participants exchanged a lot of new, crucial knowledge. Very few people put forward the sort of knowledge that might jeopardise their chances of winning.

In effect, e-group members were co-operating, but not collaborating. One of the interviewees believed that it would be more accurate to say that the forum was used for exchanging information rather than knowledge. It was his responsibility to transform into knowledge the hints and tips that he received as information. There is evidence that some higher level knowledge sharing took place off-list where members of smaller groups were banded in clique relationships in such settings more unique, "high-risk", unique insight is likely to be exchanged (Sawyer, Eschenfelder, \& Heckman, 2000, p. 196). Postings to this e-group reveal the creation of sub-groups to tackle particular problems associated with the CipherChallenge, and one questionnaire respondent explained how he, along with all his sub-group colleagues, managed to solve stage 9 through membership of TCBGroupEffortStage9RealMember. The five individuals who actually won the challenge recognised the value of working together as a group of five off-line. They describe themselves as "a team from day one" (Almgren et al., 2000, p. 4).

The initial review of postings to the e-group raised suspicions that access to, and provision of, knowledge was of far greater importance to the group's membership than social relationships. Answers to the questionnaire survey confirmed this finding. The in-depth interviews provided the opportunity to discuss this issue. A number of explanations were offered as to why social relationships were unimportant to the CipherChallenge participants. They are presented as suggestions here:

- Topic of the discussions: code breaking is an intellectual rather than social pursuit and it was intellectual, rather than emotional, bonds that pulled the e-group members together.

- Clarity of the e-group's purpose: the membership understood that the primary purpose of the group was information provision on the highly technical topic of code breaking and therefore the membership focused on this.

- Passion and interest for the topic: the strength of passion and interest for the topic was such that the group did not need additional props (such as significant social relationships) for its survival.

- The demographics of the membership: the membership was predominantly male - the lack of female members, who often provide the social glue in groups, lowered the chance of relationships forming.

- Prospects for interactions in the real world: there was little prospect of e-group members ever meeting in the real world so any investment in friendship was unlikely to lead very far.

\section{Applicability of findings to the business environment}

Managers are interested in the workings of CoPs since "they offer an opportunity to derive templates or frameworks for the creation of organisational knowledge at a number of levels 
(the working group, the firm, the sector) in the interests of improved performance" (Davenport \& Hall, 2002, p. 172). The results of this study highlight issues that businesses may wish to consider when there are plans to create virtual communities of practice to meet corporate goals, particularly with reference to furnishing environments where employees are willing to work collaboratively in the creation of new knowledge.

One of the key challenges when setting up a virtual community is how to motivate participation. The findings from the study of the CipherChallenge e-group indicate that offering the hard/explicit reward of access to individual learning is important to attracting people into a community, but will not necessarily mean that they will give, as well as take, from it. Of the rewards for knowledge sharing outlined in Table 1, potential access to the soft rewards of enhanced reputation and personal satisfaction are important in encouraging individuals to engage in a group's dialogue, particularly if the work of the group is considered intellectually challenging. These incentives, however, have to squared with the provision of a set of desirable social conditions, as given in Table 2, such as ensuring that status differences do not discourage the less-experienced from participation. The scope of a group's "agenda", and the level of interest of those invited to participate, is also important. The findings presented here indicate that a narrow focus leads to action amongst enthusiastic members without the need to provide social support, nor control (for example, in the form of a highly visible moderator).

The question of social support is also interesting from the perspective of knowledge creation. One of the aims of this research was to examine the apparent willingness of individuals to help their rivals. The findings reveal limits to the extent to which participants were happy to divulge their code-breaking secrets. It is suggested that a stronger social infrastructure amongst the group's membership might have enhanced its knowledge creation capabilities through the provision of social capital: "the trust, mutual understanding, and shared values and behaviours that bind the members of human networks and make co-operation possible" (Cohen \& Prusak, 2002, p. 4). Equally, this case shows that all-inclusive membership might provide opportunities for individual learning based on information gathering, but true knowledge capital is generated in small, less public groups. Perhaps the ultimate illustration of this is that five friends located physically close to one another succeeded in winning the challenge, rather than another grouping that came together through the virtual community. The provision of social support, as well as community size, are therefore considered important to genuine collaborative efforts in knowledge creation.

These findings need to be treated with caution, however. The CipherChallenge e-group was an unusual "collaborative" working environment where there were very good reasons not to share too much with others. For example, willing e-group knowledge-sharers had to curb their enthusiasm in order to minimise the risk of issuing spoilers; lurking without obligation to participate was perceived as a means of enhancing the chance of winning the $£ 10,000$ prize. Communities within organisations have several advantages over recreational groups, such as the scope to make available a wider range of rewards for knowledge sharing, including economic rewards. They can build more robust supporting infrastructures, and promote strong beliefs about organisational ownership of individual knowledge and expertise. 


\section{Conclusions}

A number of conclusions can be drawn from this study. The case of the CipherChallenge reveals that strong social relationships are not necessarily crucial to the operation of a virtual community. However, the level of social infrastructure that supports the community contributes to the extent to which individual knowledge (as opposed to information) is shared across the membership. This also impacts the community's propensities for, and capabilities in, creating new knowledge. Observations made here indicate that the array of incentives that it is actually possible to offer community members depends on the nature of the community. In some instances a community's set-up will simply deny particular incentives. For example, in this case there were no direct economic rewards on offer for knowledge sharing. Where a range of incentives might be employed, an effective balance is one which takes into account what is valued by the community's membership. In this case, for example, where work required addressing a very demanding intellectual set of challenges, public admiration of those who were smart enough to make progress appeared to motivate them to share their learning. The study also shows that virtual communities develop their own systems of acceptable behaviour. The most commonly cited attraction of membership of the CipherChallenge e-group was for the selfish reason of enhancing individual learning opportunities, yet later visits were prompted by the desire to contribute to others' learning. Equally the activities of lurkers and free-riders were debated on the list. Even in a community where there is apparent low interest in developing interactions with others beyond straightforward information exchange, social capital is developed. This is manifest in the reciprocities that derive from the network. Just as social capital generates knowledge capital, social capital can emerge from knowledge capital in communities.

\section{Acknowledgements}

The authors would like to acknowledge the CipherChallenge e-group members who willingly participated in the study and Simon Singh.

\section{References}

Albrechtsen, H., \& Jacob, E. (1998). The dynamics of classification systems as boundary objects for cooperation in the electronic library. Library Trends, 47(2), 293-312.

Almgren, F., Andersson, G., Granlund, T., Ivansson, L., \& Ulfberg, S. (2000). How we cracked the code book ciphers (Online). Available: http://answers.codebook.org/codebook_solution.pdf (2003, 23 May).

Bock, G. W., \& Kim, Y.-G. (2002). Breaking the myths of rewards: An exploratory study of attitudes about knowledge sharing. Information Resources Management Journal, 15(2), 14-21.

Boland, R. J., \& Tenkasi, R. V. (1995). Perspective making and perspective taking in communities of knowing. Organization Science, 6(4), 350-363.

Briers, M., \& Chua, W. F. (2001). The role of actor-networks and boundary objects in management accounting: A field study of the implementation of activity-based costing. Accounting Organizations and Society, 26(3), 237-269.

Cohen, D., \& Prusak, L. (2002). In good company: how social capital makes organizations work. Boston: Harvard Business School Press. 
Davenport, E., \& Hall, H. (2002). Organizational knowledge and communities of practice. In B. Cronin (Ed.), Annual review of information science and technology, Vol. 36 (pp. 171-227). Medford, NJ: Information Today.

Denscombe, M. (1998). The good research guide. Buckingham: Open University Press.

Faraj, S., \& Wasko, M. M. (c2001). The web of knowledge: An investigation of knowledge exchange in networks of practice (Online). Available: http://opensource.mit.edu/papers/Farajwasko.pdf (2003, 5 June).

Galison, P. (1997). Trading zone: Co-ordinated action and belief. In P. Galison (Ed.), Image and logic: A material culture of microphysics (pp. 781-884). Chicago: University of Chicago Press.

Gray, P. H., \& Meister, D. (2001). Anomaly reconciliation by discretionary groups; available: http://business.queensu.ca/ kbe/docs/wp_01-05.pdf (2003, 27 January).

Hall, H. (2001a). Input friendly intranets: Motivating knowledge sharing across intranets. Journal of Information Science, 27(3), 139-146.

Hall, H. (2001b). Social exchange for knowledge exchange. Paper presented at the Managing knowledge: Conversations and critiques, 10-11 April 2001, University of Leicester (full text available from http://www.bim.napier.ac.uk/esis/ about_us/hazel_publications.html).

Hall, H. (2003). Borrowed theory: Applying exchange theories in information science research. Library and Information Science Research, 25(3), 287-306.

Harvey, F., \& Chrisman, N. (1998). Boundary objects and the social construction of GIS technology. Environment and Planning A, 30(9), 1683-1694.

Henderson, K. (1998). The role of material objects in the design process: A comparison of two design cultures and how they contend with automation. Science Technology and Human Values, 23(2), 139-174.

Huang, J. C., Newell, S., \& Galliers, R. (2002). Inter-organizational communities of practice. Paper presented at the third European conference on organizational knowledge, learning and capabilities, 5-6 April, Athens, Greece.

Huberman, B. A., \& Hogg, T. (1994). Communities of practice: Performance and evolution (pp. 1-23). Palo Alto, CA: Xerox Palo Alto Research Center.

Jarvenpaa, S. L., \& Staples, D. (2001). Exploring perceptions of organizational ownership of information and expertise. Journal of Management Information Systems, 18(1), 151-183.

Lave, J., \& Wenger, E. (1991). Situated learning: Legitimate peripheral participation. Cambridge: Cambridge University Press.

Lerner, J., \& Tirole, J. (2002). Some simple economics of open source. Journal of Industrial Economics, L2 (June), 197-234.

Rettstatt, C. (2003). Children and teens online: New generations, new scenarios. Paper presented at the sixth international virtual communities conference, 16-17 June, London.

Rheingold, H. (1994). The virtual community: Finding connection in a competitive world. London: Secker and Warburg.

Robinson, L. (2000). Boundary objects, spaces, and people: Creating the National Gallery of the Spoken Word (Online). Available: http://www.lib.msu.edu/robin179/presentations/saa/boundary.htm (2003, 28 January).

Sawyer, S., Eschenfelder, K., \& Heckman, R. (2000). Knowledge markets: Cooperation among distributed technical specialists. In T. Srikantaiah, \& M. Koenig (Eds.), Knowledge management for the information professional (pp. 181-204). Medford, NJ: Information Today.

Shabka, N. (2003). Structured anarchy: A study from the educational sector. Paper presented at the sixth international virtual communities conference, 16-17 June, London.

Singh, S. (1999). The code book. London: Fourth Estate.

Singh, S. (2000). The story behind the Cipher Challenge (News group contribution). Available: http://groups.yahoo.com/ group/CipherChallenge/message/4491 (2003, 3 June).

Star, S. L., \& Griesemer, J. R. (1989). Institutional ecology, "translations" and boundary objects: Amateurs and professionals in Berkeley's Museum of Vertebrate Zoology. Studies of Social Science, 19(3), 387-420.

Strubing, J. (1998). Bridging the gap: On the collaboration between symbolic interactionism and distributed artificial intelligence in the field of multi-agent systems research. Symbolic Interaction, 21(4), 441-463.

Welcome (1999). (News group contribution) Available: http://groups.yahoo.com/group/CipherChallenge/message/1 (2003, 22 May).

Wenger, E., \& Snyder, W. (2000). Communities of practice: The organizational frontier. Harvard Business Review (January/February), 139-145. 
Hazel Hall is a Senior Lecturer in the School of Computing at Napier University in Edinburgh, Scotland, where she teaches and conducts research in Information Management. Her published work covers topics such as online information services provision, business information sources and services, the education and training of information professionals, and knowledge management. Her current research interests focus on factors that motivate knowledge sharing, particularly in large, distributed, information-intensive organisations. Hazel Hall holds a Masters degree in Information Management, was elected a Fellow of the Institute of Information Scientists in 2000, and is now a Fellow of the Chartered Institute of Library and Information Professionals.

Dianne Graham Since graduating with a first class degree in Business Information Management from Napier University, Edinburgh, Dianne Graham has been employed as Systems Administrator at Highland Harbours in Lochinver, Scotland for Highland Regional Council. 